\title{
Obtaining Heterogeneous Oxide Coating on Chrome-Nickel Steel in Heating-Cooling Cycles in the Air
}

\author{
Igor V. Rodionov \\ Department of Welding and Metallurgy \\ Yuri Gagarin State Technical University \\ Saratov, Russia \\ iv.rodionov@mail.ru
}

\author{
Lyubov E. Kuts \\ Department of Welding and Metallurgy \\ Yuri Gagarin State Technical University \\ Saratov, Russia \\ iv.rodionov@mail.ru
}

\author{
Irina V. Perinskaya \\ Department of Welding and Metallurgy \\ Yuri Gagarin State Technical University \\ Saratov, Russia \\ iv.rodionov@mail.ru
}

\begin{abstract}
We investigated an impact of technological conditions of oxidizing X12CrNiTi18-9 stainless steel implants in repeated heating-cooling cycles in the air on morphological features of resulting metal oxide coating. Our findings confirmed that generated coating had a high morphological heterogeneity of its surface structure with dimensional parameters in the microand nanometer range of values. The effect of structurally heterogeneous metal oxide coating on the osseointegration capacity of steel implant surface was experimentally established.
\end{abstract}

Keywords - steel implants, thermal oxidation in the air, heatingcooling cycles, metal oxide coating, structural and morphological features of the surface

\section{INTRODUCTION}

Stainless chrome-nickel steel, possessing bio-inertia along with physical-mechanical properties required for the efficient performance of medical products, is widely used in production of various orthopedic systems and implants. To ensure proper engraftment, steel medical products, such as bone implants for osteosynthesis, must retain certain physicochemical and biomechanical characteristics of their surfaces, which can be achieved by means of biocompatible morphologically heterogeneous porous coatings from various ceramic materials.

Surface treatment of medical implants is performed by airthermal, vacuum-condensation or physico-chemical deposition methods [1-9]. Among those, air-thermal oxidation processes are technologically simple to implement, require low energy consumption and no additional materials for generating biocompatible oxide films and coatings [10-16].

Majority of the previously performed studies on oxidation of metals and alloys was devoted to the development of coatings with high wear resistance, electrical insulating properties, as well as protective properties provided by the presence of significant hardness and structural density in oxide coatings with minimal porosity, low roughness and low morphological heterogeneity of the surface (N.D. Tomashov, N.P. Zhuk, G.V. Akimov, A.N. Frumkin, V.I. Lainer, M.I. Tsipin, V.A. Kistyakovsky, S.Ya. Grilikhes, V.I. Arkharov, F. Todt, U.R. Evans, A.E. Jenkins and others). Coatings with such characteristics are marginally effective and unsuitable for use on medical implants, where relatively high open porosity and developed surface structure are required.

At present, considerable attention in the manufacture of steel orthopedic implants for external osteosynthesis is paid to the metal oxide coatings. Such coatings with specific phase and chemical compositions, as well as heterogeneous surface structure, can provide a high level of implant engraftment, given their surface ability to exhibit high osteoconductive properties and effective osseointegration [13-15].

Metal oxide coatings created on implants by various methods of thermal oxidation protect the metal base from the corrosive effects inside the human body due to their electrochemical protective quality, thus significantly reducing the tendency of the implants to corrode [17-25]. Passivated, corrosion-resistant implants do not cause prolonged allergic reactions, nor do they have a toxicological effect on surrounding biostructures, which implies high biocompatibility of such implant products.

To ensure strong adhesion of coatings to the bone tissue, it is necessary to create a pronounced roughness and morphological heterogeneity of their surfaces.

Compared to the surface with a smooth, homogeneous microrelief, structurally heterogeneous and openly porous surfaces of oxide coatings provide both better contact growth of the bone and more intensive course of tissue reactions. Hence, the developed oxidized surface promotes active penetration of bone cellular structures into the pores and 
microcavities of the oxide layer, resulting in improved osseointegration of implants and accelerated osteogenesis.

One of conventional methods of air-thermal oxidation is oxidation in the air reaction medium, which makes it possible to create oxide films and coatings on various metals and alloys in order to increase their anticorrosive properties and mechanical strength of the surface. Using this oxidation method, it is possible to form oxide layers with specified volume and surface structures, as well as required roughness, porosity and size of metal oxide particles.

Thus, air-thermal oxidation technological processes can be employed to produce oxide coatings on medical metal implants, specifically - coatings capable of fusing with the bone tissue.

Thus, the goal of this study was the development of airthermal metal oxide coatings with heterogeneous micro- and nanostructures on steel medical implants designed for osteosynthesis.

\section{Methods OF EXPERIMENTAL STUdIES}

Implant samples in the form of screw rods for transosseous osteosynthesis were manufactured from biocompatible stainless steel, X12CrNiTi18-9 (Russian National Standard: GOST 5632-72). The surface of implants was sandblasted by abrasive corundum $\mathrm{Al} 2 \mathrm{O} 3$ with a particle size of $250 \mu \mathrm{m}$ at an air-abrasive jet pressure of $0.67 \mathrm{MPa}$ for $30 \mathrm{~s}$ in order to create an initial microroughness providing greater structural heterogeneity of the metal oxide coating to be formed.

After preliminary sandblasting, the steel samples were subjected to ultrasonic cleaning in an alcohol solution at a frequency of $22 \mathrm{kHz}$ for $3 \mathrm{~min}$ to remove the existing greasy films, thus improving an attachment of created metal oxide layers to the substrate.

Air-thermal oxidation was conducted using an experimental tubular electric resistance furnace in the form of a quartz tube $40 \mathrm{~mm}$ in diameter with a nichrome spiral heating element and asbestos thermal insulation.

The voltage values on the nichrome heater were set with a laboratory autotransformer and corresponded to specific temperature values of the oxidizing air in the furnace working zone.

The oxidation regimen provided heating the implants in the furnace up to 400 and $500^{\circ} \mathrm{C}$ with exposure times of $1.0 \mathrm{~h}$ at each temperature. The heating procedure was accompanied by implant removal from the furnace for 5-10 s at $10 \mathrm{~min}$ intervals for short-term cooling.

Structure formation of metal oxide coatings in multiple heating-cooling cycles of the samples in air was characterized by cracking (fragmentation) of oxide particles to produce coatings with heterogeneous fractured micro- and nanostructures, which significantly increased the osteoconductive qualities and geometric bioactivity of oxidized surfaces.

The chemical composition of the coatings was identified from the spectra of chemical elements on several micro-areas of the oxidized surface by energy-dispersive X-ray spectroscopy (EDXS) using the INCAPentaFETx3 detector, OXFORD Instruments PLC.

Morphological characteristics of oxide coatings were investigated by the contactless determination of dimensional parameters of protruding particles and existing surface cavities, including pores.

For such measurements and data processing, we used an AGPM-6M image analyzer of microstructures with a microscope, Sony digital camera, and a computer program for processing microimages. The surface morphology of obtained coatings at submicrometer and nanometer scales was studied by scanning electron microscopy (SEM) using analytical equipment MIRA II LMU, Tescan.

The surface roughness of the formed coatings was studied by the profilometry method based on the measurements of the microroughness parameters $\mathrm{Ra}, \mathrm{Rz}, \mathrm{Rmax}, \mathrm{Sm}$ using ten basic lines with subsequent mathematical processing of the measurement results.

Roughness testing equipment was represented by the microprocessor-based Caliber-117071 profilographprofilometer, along with a mobile device HOMMEL Tester T1000 Basic (Hommel Etamic) to control for microroughness.

\section{STUDY RESUlTS AND THEIR ANALYSIS}

In the technological conditions of air-thermal oxidation of steel implants with repeated heating-cooling cycles, the particles of metal oxides, representing the metals in the alloy, were formed on the surface.

These particles, due to implementation of thermal cycles, were exposed to rapidly varying internal stress in the alloy, which caused surface cracking; hence, resulting coating acquired fractured micro- and nanostructures. For example, at an air-thermal oxidation temperature of $400^{\circ} \mathrm{C}$ and treatment time of $1.0 \mathrm{~h}$, the morphological structure of the stainless steel coating was characterized by the presence of numerous, differently oriented protrusions and open pores unevenly distributed over the surface (Fig. 1).

The nature of such distribution of the coating particles and pores, as well as their dimensional parameters, provided high heterogeneity of the metal oxide coating surface structure, which improved osseointegration of oxidized steel implants, because bone cellular structures were able to grow into the microroughness elements of the coating.

The values of dimensional parameters of the coating structural elements obtained at $\mathrm{t}=500^{\circ} \mathrm{C}$ exceeded the values of the surface coating parameters obtained at $\mathrm{t}=400^{\circ} \mathrm{C}$. In the structure of the former coating, numerous open pores and irregularities were observed (Fig. 2). Such morphologically developed coating was capable of exhibiting high bioadhesiveness with possible strong integration of metal oxides with the bone tissue.

Via software processing of coating microimages, we used optical computing of the surface structure of metal oxide layers to identify dimensional characteristics and uniformity in 
the distribution of structural elements (particles and pores) on thermally modified surfaces (Table 1).

It has been established that the microstructure of the coatings had a different degree of pronounced morphology, with particle and pore sizes significantly differing depending on the air-thermal oxidation temperature of the implants (Table 1).

Furthermore, the nature of distribution of structural elements in oxidized surfaces was changing substantially, which, in turn, caused the variation of the total open porosity in the range of $30-48 \%$.

The difference in the morphological structure of the coatings obtained at different oxidation temperatures was associated with direct effect of treatment temperatures on the growth rate and the nature of the structure formation in oxides: metal oxide matrices with increased number of finely dispersed crystals and micropores were forming under higher temperatures (Table 1).

Profilometry studies also showed the effect of air-thermal oxidation temperatures on surface roughness parameters of the coatings (Table 2).
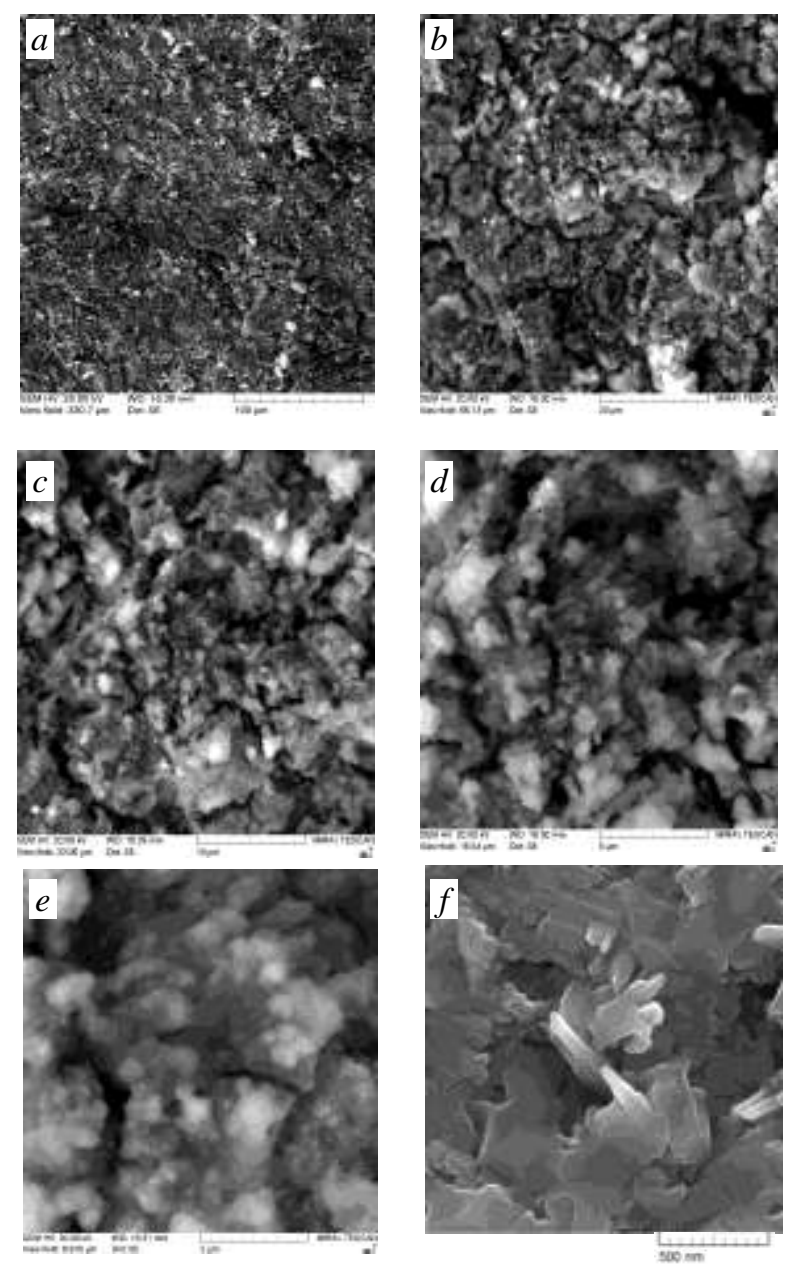

Fig 1. Heterogeneous structure of the metal oxide coating on X12CrNiTi18-9 steel obtained in repeated heating-cooling cycles at $t=500^{\circ} \mathrm{C}$ and $\tau=1.0 \mathrm{~h}$ (cooling for $5-10 \mathrm{~s}$ every $10 \mathrm{~min}$ of heating): $a-\times 1000, b-\times 5000, c-\times 10000, d-\times 50000, e-\times 120000$.
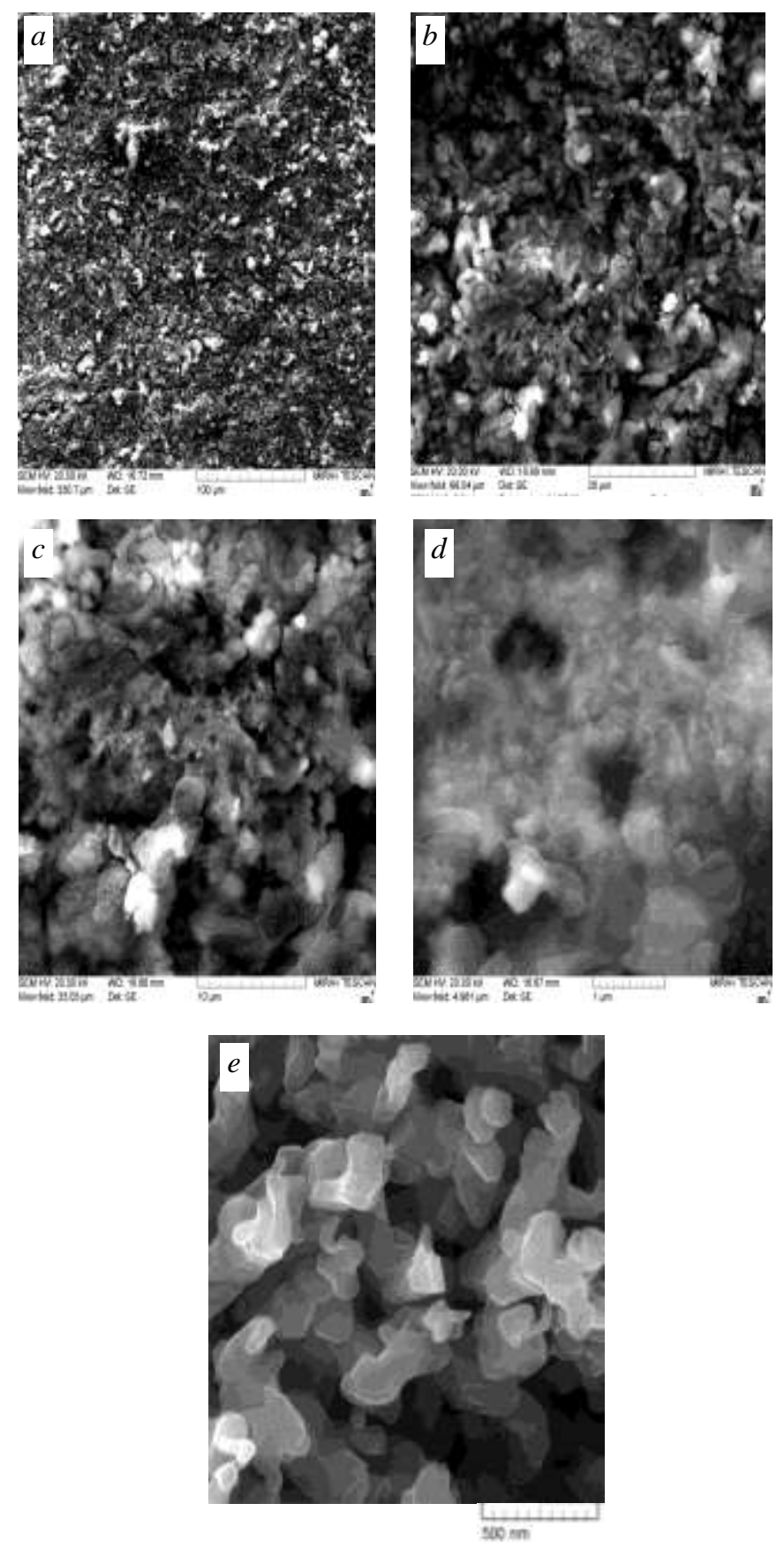

Fig 2. Heterogeneous structure of the metal oxide coating on X12CrNiTi18-9 steel obtained in repeated heating-cooling cycles at $t=400^{\circ} \mathrm{C}$ and $\tau=1.0 \mathrm{~h}$ (cooling for $5-10 \mathrm{~s}$ every $10 \mathrm{~min}$ of heating): $a-\times 1000, b-\times 5000, c-\times 10000, d-\times 20000, e-\times 50000, f-\times 120000$. 
TABLE I. MORPhologicAl CHARACTERISTICS OF METAl OXIDE COATINGS OBTAINED ON STEEL IMPLANTS AT DiFFERENT TEMPERATURES AND $\mathrm{T}=1.0 \mathrm{H}$ (OPTICAL AREA OF INVESTIGATED SURFACE, $\left.\mathrm{S}=2.71 \mathrm{MM}^{2}\right)$

\begin{tabular}{|c|c|c|c|c|c|c|c|c|}
\hline \multirow{2}{*}{$\begin{array}{c}\text { Regimens } \\
\text { of Air- } \\
\text { Thermal } \\
\text { Oxidation }^{\mathrm{a}}\end{array}$} & \multicolumn{8}{|c|}{ Morphological Characteristics of Coatings } \\
\hline & \multicolumn{4}{|c|}{ Particles } & \multicolumn{4}{|c|}{ Pores } \\
\hline$t,{ }^{\circ} \mathrm{C}$ & $\begin{array}{c}\text { No. of sample optical } \\
\text { area }\end{array}$ & $\begin{array}{c}\text { Number } \\
\text { per } \\
\text { optical } \\
\text { area } \\
\end{array}$ & $\begin{array}{c}\text { Average size }, \\
\mu \mathrm{m}\end{array}$ & Dispersion, $\mu \mathrm{m} 2$ & $\begin{array}{c}\text { Number } \\
\text { per } \\
\text { optical } \\
\text { area } \\
\end{array}$ & $\begin{array}{c}\text { Average size } \\
\mu \mathrm{m}\end{array}$ & Dispersion, $\mu \mathrm{m} 2$ & Total porosity, $\%$ \\
\hline 400 & $\begin{array}{l}1 \\
2 \\
3\end{array}$ & $\begin{array}{l}360 \\
445 \\
472\end{array}$ & $\begin{array}{l}35.73 \\
35.47 \\
31.70\end{array}$ & $\begin{array}{l}95.47 \\
100.1 \\
101.3\end{array}$ & $\begin{array}{l}740 \\
840 \\
834\end{array}$ & $\begin{array}{l}30.47 \\
30.48 \\
31.95\end{array}$ & $\begin{array}{l}81.93 \\
83.97 \\
77.20\end{array}$ & $\begin{array}{l}30 \\
33 \\
31\end{array}$ \\
\hline 500 & $\begin{array}{l}1 \\
2 \\
3\end{array}$ & $\begin{array}{l}595 \\
648 \\
678 \\
\end{array}$ & $\begin{array}{l}21.35 \\
21.31 \\
19.88 \\
\end{array}$ & $\begin{array}{l}87.1 \\
92.0 \\
99.76 \\
\end{array}$ & $\begin{array}{l}965 \\
911 \\
1129 \\
\end{array}$ & $\begin{array}{l}37.06 \\
40.51 \\
35.28 \\
\end{array}$ & $\begin{array}{l}72.81 \\
83.32 \\
52.26 \\
\end{array}$ & $\begin{array}{l}41 \\
46 \\
48\end{array}$ \\
\hline
\end{tabular}

a. Oxidation of the samples was conducted in the conditions of repeated heating-cooling cycles: cooling was carried out for 5-10 s every 10 min of heating.

It has been established that all microroughness parameters increased with an increase in the processing temperature of stainless steel, which agreed with experimental data obtained in the course of optical microscopic studies.

The chemical composition of obtained coatings had different weight ratios of the elements, which could be explained by chemical heterogeneity of the base alloy and by the peculiarities of oxidation and structure formation mechanisms of oxide layers on heterophase metallic materials (Table 3).

Compositions of the coatings were characterized by the presence of significant amounts of nickel, aluminum, titanium and chromium, which, in the form of compounds with oxygen, could give the surface high biocorrosion resistance necessary for the functioning of steel implants inside the human body.

Using described technological process, we manufactured experimental implants of the standard design in the form of screw rods for transosseous osteosynthesis (Fig. 3).

TABLE II. SURFACE ROUGHNESS OF STEEL IMPLANT OXIDE SURFACES AT VARIOUS TEMPERATURES OF AIR-THERMAL OXIDATION

\begin{tabular}{|c|c|c|c|c|c|c|c|}
\hline \multicolumn{8}{|c|}{ Roughness Parameters, $\mu \mathrm{m}$} \\
\hline \multicolumn{2}{|c|}{$R a$} & \multicolumn{2}{|c|}{$R z$} & \multicolumn{2}{|c|}{$R \max$} & \multicolumn{2}{|c|}{$S m$} \\
\hline \multicolumn{8}{|c|}{ Oxidation temperature, ${ }^{\circ} \mathrm{C}(\tau=1.0 \mathrm{~h})$} \\
\hline 400 & 500 & 400 & 500 & 400 & 500 & 400 & 500 \\
\hline \multicolumn{8}{|c|}{ Mean parameter value $(n=10)$} \\
\hline 2.3 & 2.9 & 12.6 & 13.9 & 24.7 & 28.9 & 53.6 & 59.8 \\
\hline
\end{tabular}

TABLE III. CHEMICAL COMPOSITION OF MORPHOLOGICALLY HeTEROGENEOUS METAL OXIDE COATINGS ON X12CRNiTi18-9 STEEL OBTAINED BY AIR-THERMAL OXIDATION AT VARIOUS TEMPERATURES AND $\mathrm{T}=1.0 \mathrm{H}$

\begin{tabular}{|c|c|c|c|c|c|c|c|c|}
\hline \multirow{2}{*}{$\begin{array}{c}\text { Oxidation } \\
\text { Temperatures, }\end{array}$} & \multicolumn{7}{|c|}{$\mathbf{C}$ Chemical Composition of the Coating, weight \% } \\
\cline { 2 - 9 } & $\boldsymbol{O}=\mathbf{~ 1 0 0 )}$ \\
\hline 400 & 44.44 & 8.98 & - & 1.27 & 18.17 & 1.28 & 23.07 & 2.79 \\
500 & 39.81 & 3.46 & - & 2.10 & 28.92 & 1.44 & 14.77 & 9.58 \\
\hline
\end{tabular}

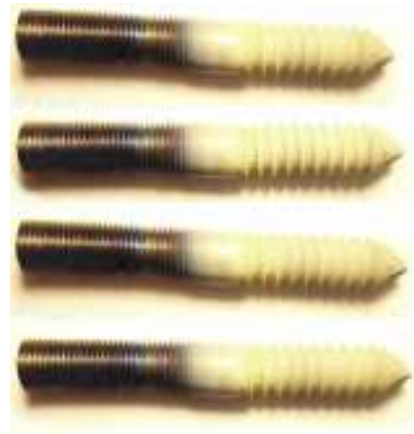

$a$

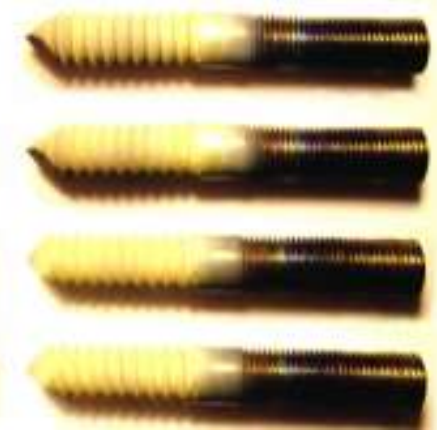

$b$
Fig 3. Experimental samples of transosseous rod implants from X12CrNiTi18-9 steel with metal oxide coatings obtained in repeated heatingcooling cycles in air (cooling for $5-10 \mathrm{~s}$ every $10 \mathrm{~min}$ of heating): $a-\mathrm{t}=400^{\circ} \mathrm{C}$ and $\tau=1.0 \mathrm{~h} ; b-\mathrm{t}=500^{\circ} \mathrm{C}$ and $\tau=1.0 \mathrm{~h}$.

These prototypes are further planned for clinical testing on laboratory animals to identify their ability for effective engraftment in bone tissue.

\section{LABORATORY TESTING OF TRANSOSSEOUS STEEL IMPLANTS WITH AIR-THERMAL METAL OXIDE COATINGS}

Tests of steel samples were carried out on laboratory animals, specifically - on the rabbits of the Dutch Red breed, in which experimental rod implants were screwed into their tibiae. They were standard screw rods for osteosynthesis, used in external fixation devices.

Animals under neuroleptanalgesia with Rompun ${ }^{\circledR}$ and Zoletil ${ }^{\circledR}$ were subject to a flexion fracture of their tibiae in the middle third of the diaphysis; then, channels were drilled in bone fragments for screwing rod implants.

Given that strength characteristics of the bone are significantly different at different sites of its length, the 
implants of each series were installed in both metaphyseal and diaphyseal parts of the bones.

Implants were screwed in manually with the aid of a handle from the apparatus set of G.A. Ilizarov, followed by a closed reposition of bone fragments. Their external fixation was conducted in the apparatus of original design, consisting of brackets and a bar with multiple holes.

In the postoperative period, all animals underwent a preventive antibiotic therapy with cefazoline, as well as the cleaning of the implant-bone contact zone with a $3 \%$ solution of hydrogen peroxide. Clinical and morphological studies were also performed at this stage.

The test period lasted for 50 days, after which the implants were removed from the animals and examined for osseointegration capacity of their surfaces.

In addition, a clinical assessment of implant osseointegration properties was carried out by investigating rabbit condition characteristics, such as: recording their body temperature, behavior, limb's ability to support the body weight, micromobolity of implants, the response of animals to implant clamps, the development of inflammatory complications (using a microbiological study of smears and pathological research in the course of dead animal autopsy), and also the level of sample rod resistance to unscrewing.

Implants were divided into three experimental groups. Group 1 (control) included implants without metal oxide coating; group 2 - implants with metal oxide coating, obtained during the multiple heating-cooling thermal cycles in air at $\mathrm{t}=$ $400^{\circ} \mathrm{C}$ and $\tau=1.0 \mathrm{~h}$, while group 3 consisted of implants with metal oxide coating, obtained with multiple heating-cooling thermal cycles in air at $\mathrm{t}=500^{\circ} \mathrm{C}$ and $\tau=1.0 \mathrm{~h}$

Before the formation of coatings on implants, their surface was prepared using a certain technological sequence of pretreatment operations (Fig. 4).

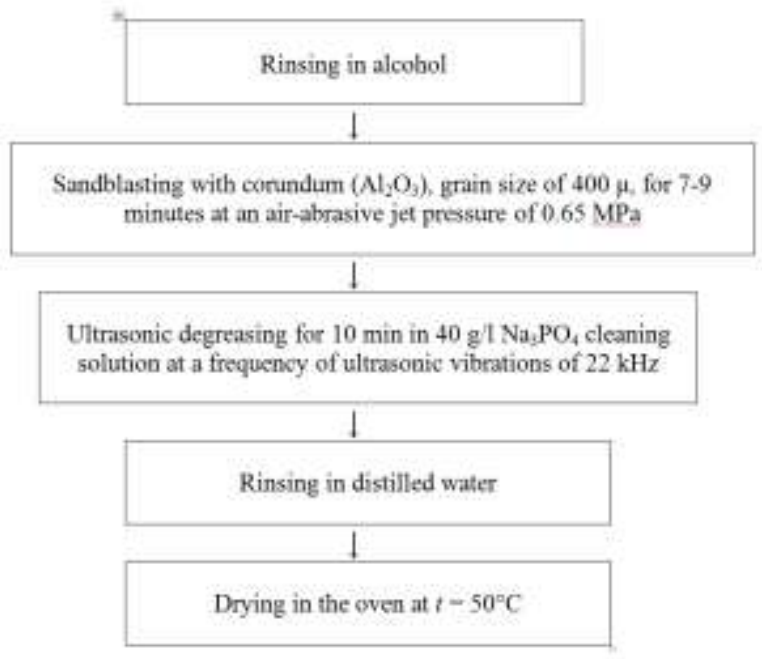

Fig 4. Route diagram of operations for preliminary processing (preparation) of implant surfaces.
Due to preliminary surface treatment, such initial parameters as microroughness, chemical activity, structural heterogeneity, and purity were ensured.

As a result of laboratory tests of implants, it was established that samples of control group did not show any pronounced osseointegration capacity of their surfaces due to the absence of its osteoconductive properties.

At the end of 50 days of functioning in the animals, samples of this group did not provide high level of engraftment and increased durability of anchoring in the bone, as evidenced by the absence of a significant amount of bone regenerate on the surface of the implants (Fig. $5 a$ ).

Samples of the experimental groups 2 and 3 were superficially integrated with the surrounding bone tissue and firmly intergrown with the biostructures at the end of the test period.

When these samples were extracted, the presence of large fragments of the newly formed bone, firmly connected to the morphologically heterogeneous metal-oxide coating (Fig. $5 b$ and $c$ ), was noted on their surfaces.

This implied significant influence of created micro- and nanostructured coatings on the osteoconductivity of steel implant surface and their ability to firmly fuse with bone structures.
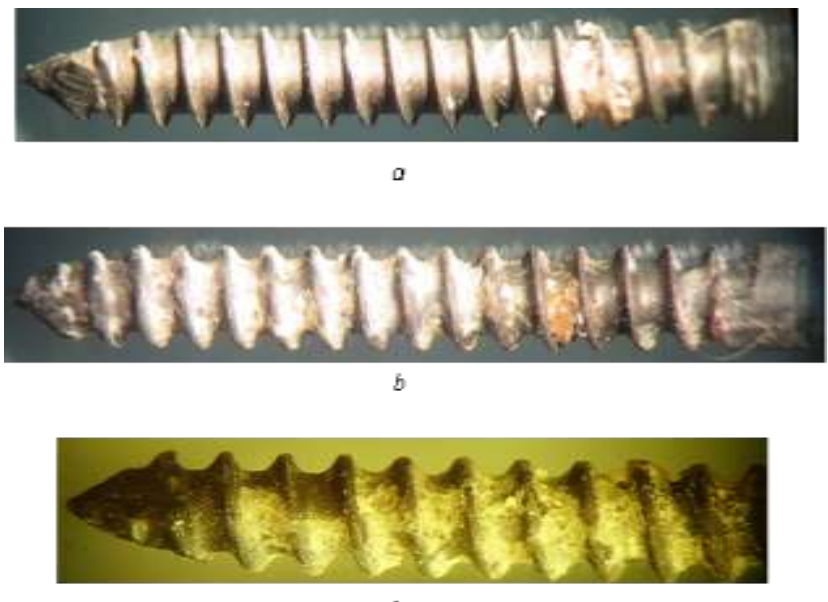

Fig 5. Samples of transosseous steel implants of the groups $1(a), 2(b)$ and $3(c)$ after 50 days of functioning in the bone tissue of laboratory animals.

\section{CONCLUSIONS}

As a result of our experimental studies, it has been established that morphologically heterogeneous metal oxide coatings with micro- and nanoscale structural elements are formed under technological conditions of oxidation of transosseous implants made from X12CrNiTi18-9 steel undergoing multiple heating-cooling thermal cycles in air at the temperatures of 400 and $500^{\circ} \mathrm{C}$ for the total duration of 1.0 h.

Such manufacturing procedure has been found to give the implant surface pronounced osteoconductive qualities. We 
therefore recommend using the developed coatings in steel transosseous implants employed in external osteosynthesis apparatus in the course of skeletal bone fracture treatment.

\section{Acknowledgment}

This study was supported by the Russian Federation Ministry of Education and Science within the framework of the Program on Scientific Research at Universities (project No. 11.1943.2017/PP).

\section{References}

[1] I.V. Rodionov, "Microstructure of biocompatible steam-heat oxide coatings on titanium implants," Metal Science and Heat Treatment, vol. 55, nos. 11-12, pp. 599-602, 2014

[2] R. Hazan, R. Brener, U. Oron, "Bone growth to metal implants is regulated by their surface chemical properties," Biomaterials, vol. 14, no. 8, pp. 570-574, 1993.

[3] L. Le Guéhennec, A. Soueidan, P. Layrolle, Y. Amouriq, "Surface treatments of titanium dental implants for rapid osseointegration," Dent. Mater., vol. 23, pp. 844-854, 2007.

[4] K. Kuroda, R. Ichino, M. Okido, and O. Takai, "Effects of ion concentration and $\mathrm{pH}$ on hydroxyapatite deposition from aqueous solution onto titanium by the thermal substrate method," J. Biomed. Mater. Res., vol. 61, no. 3, pp. 354-359, 2002.

[5] S. Fujibayashi, M. Neo, H. M. Kim, T. Kokubo, and T. Nakamura, "Osteoinduction of porous bioactive titanium metal," Biomaterials, vol. 25, no. 3, pp. 443-450, 2004

[6] Y.T. Sul, C.B. Johansson, S. Petronis et al., "Characteristics of the surface oxides on turned and electrochemically oxidized pure titanium implants up to dielectric breakdown: the oxide thickness, micropore configurations, surface roughness, crystal structure and chemical composition," Biomaterials, vol. 23, no. 2, pp. 491-501, 2002.

[7] J.P. Schreckenbach, G. Marx, F. Schlottig, M. Textor, N.D. Spencer, "Characterization of anodic spark-converted titanium surfaces for biomedical applications,” J. Mater. Sci.-Mater. M., vol. 10, no. 8, pp. 453-457, 1999.

[8] B. Yang, M. Uchida, H.M. Kim, X. Zhang, T. Kokubo "Preparation of bioactive titanium metal via anodic oxidation treatment," Biomaterials, vol. 25, no. 6, pp. 1003-1010, 2004.

[9] Y. Zhao, T. Xiong, and W. Huang, "Effect of heat treatment on bioactivity of anodic titania films," Appl. Surf. Sci., vol. 256, no. 10, pp. 3073-3076, 2010

[10] B. Feng, J. Weng, B.C. Yang, S.X. Qu, X.D. Zhang, "Characterization of surface oxide films on titanium and adhesion of osteoblast," Biomaterials, vol. 24, no. 25, pp. 4663-4670, 2003.

[11] A. Fomin, M. Fomina, V. Koshuro, I. Rodionov, A. Zakharevich, A. Skaptsov, "Structure and mechanical properties of hydroxyapatite coatings produced on titanium using plasma spraying with induction preheating," Ceram. Int., vol. 43, pp. 11189-11196, 2017

[12] V.A. Koshuro, M.A. Fomina, I.V. Rodionov, A.A. Fomin, "Nanoporous Structure of Coatings Formed by Thermal Spraying of Aluminum Oxide with Further Microarc Oxidation on Titanium Alloy VT6 Implants," Biomed. Eng., vol. 50, no.1, pp. 54-57, 2016.

[13] A. Fomin, S. Dorozhkin, M. Fomina, V. Koshuro, I. Rodionov, A Zakharevich, N. Petrova, A. Skaptsov, "Composition, structure and mechanical properties of the titanium surface after induction heat treatment followed by modification with hydroxyapatite nanoparticles," Ceram. Int., vol. 42, no. 9, pp. 10838-10846, 2016.

[14] A.A. Fomin, A.B. Steinhauer, I.V. Rodionov, M.A. Fomina, A.M. Zakharevich, A.A. Skaptsov, A.N. Gribov, and Ya.D. Karsakova, "Properties of Titanium Dioxide Coatings Produced by InductionThermal Oxidation of VT1-00 Alloy," J. Frict. Wear, vol. 35, no. 1, pp. 32-39, 2014.
[15] A.A. Fomin, A.B. Steinhauer, I.V. Rodionov, M.A. Fomina, A.M Zakharevich, "Nanocrystalline Structure of Surface Layer of TechnicalPurity Titanium Subjected to Induction-Thermal Oxidation," Tech. Phys. Lett., vol. 39, no. 11, pp. 969-971, 2013.

[16] T.R. Rautray et al., "Surface modification of titanium and titanium alloys by ion implantation," Journal of Biomedical Materials Research, Part B: Applied Biomaterials, vol. 93, no. 2, pp. 581-591, 2010.

[17] P.K. Ajikumar et al., "Effect of reactive gas composition on the microstructure, growth mechanism and friction coefficient of $\mathrm{TiC}$ overlayers," Int. J. Refract. Met. H, vol. 31, pp. 62-70, 2012.

[18] M. Shafiq et al., "Pulsed ion beam-assisted carburizing of titanium in methane discharge," Chinese Phys. B, vol. 19, no. 1, p. 012801, 2010

[19] J.J. Dai et al., "Microstructure and Properties of Laser Surface Carburized Titanium and Titanium Alloys," Adv. Mat. Res., vol. 936, pp. 1086-1090, 2014

[20] C. Boonruang, S. Thongtem, "Fast processing technique for TiC coatings on titanium," Chiang Mai J. Sci., vol. 37, pp. 206-212, 2010.

[21] S. Farè et al., "Properties of nitrided layers formed during plasma nitriding of commercially pure $\mathrm{Ti}$ and $\mathrm{Ti}-6 \mathrm{Al}-4 \mathrm{~V}$ alloy," Surf. Coat. Tech., vol. 206, no. 8, pp. 2287-2292, 2012.

[22] A. Nishimoto, T.E. Bell, T. Bell, "Feasibility study of active screen plasma nitriding of titanium alloy," Surf. Eng., vol. 26, no. 1, pp. 74-79, 2010.

[23] S.N. Dahotre et al., "An integrated experimental and computational approach to laser surface nitriding of Ti-6Al-4V," Appl. Surf. Sci., vol. 271, pp. 141-148, 2013.

[24] G. Di Girolamo et al., "Microstructure and mechanical properties of plasma sprayed alumina-based coatings," Ceram. Int., vol.. 40, no. 8, pp. 12861-12867, 2014

[25] I.V. Rodionov, "Application of the air-thermal oxidation technology for producing biocompatible oxide coatings on periosteal osteofixation devices from stainless steel," Inorg. Mater.: Appl. Res., vol. 4, no. 2, pp. 119-126, 2013. 